\title{
Role of ABCG2 in Secretion into Milk of the Anti-Inflammatory Flunixin and Its Main Metabolite: In Vitro-In Vivo Correlation in Mice and Cows
}

\author{
Dafne Garcia-Mateos, Alba Maria Garcia-Lino, Indira Alvarez-Fernandez, Esther Blanco-Paniagua, \\ Alvaro de la Fuente, Ana Isabel Alvarez, and Gracia Merino
}

Department of Biomedical Sciences-Physiology, Veterinary Faculty (D.G.-M., A.M.G.-L., I.A.-F., A.I.A., G.M.), and Instituto de Desarrollo Ganadero y Sanidad Animal (D.G.-M., A.M.G.-L., I.A.-F., E.B.-P., A.F., A.I.A., G.M.), Universidad de León, Campus de Vegazana, Leon, Spain

Received November 12, 2018; accepted March 7, 2019

\section{ABSTRACT}

Flunixin meglumine is a nonsteroidal anti-inflammatory drug (NSAID) widely used in veterinary medicine. It is indicated to treat inflammatory processes, pain, and pyrexia in farm animals. In addition, it is one of the few NSAIDs approved for use in dairy cows, and consequently gives rise to concern regarding its milk residues. The $A B C G 2$ efflux transporter is induced during lactation in the mammary gland and plays an important role in the secretion of different compounds into milk. Previous reports have demonstrated that bovine ABCG2 Y581S polymorphism increases fluoroquinolone levels in cow milk. However, the implication of this transporter in the secretion into milk of anti-inflammatory drugs has not yet been studied. The objective of this work was to study the role of ABCG2 in the secretion into milk of flunixin and its main metabolite, 5-hydroxyflunixin, using $\mathrm{Abcg} 2^{(-/-)}$mice, and to investigate the implication of the Y581S polymorphism in the secretion of these compounds into cow milk. Correlation with the in vitro situation was assessed by in vitro transport assays using Madin-Darby canine kidney II cells overexpressing murine and the two variants of the bovine transporter. Our results show that flunixin and 5-hydroxyflunixin are transported by ABCG2 and that this protein is responsible for their secretion into milk. Moreover, the Y581S polymorphism increases flunixin concentration into cow milk, but it does not affect milk secretion of 5-hydroxyflunixin. This result correlates with the differences in the in vitro transport of flunixin between the two bovine variants. These findings are relevant to the therapeutics of anti-inflammatory drugs.

\section{Introduction}

The ABCG2 membrane efflux transporter is responsible for excretion from the cells of a wide variety of endogenous compounds, xenobiotics, and drugs. It is located in the apical membrane of epithelial cells of several tissues and organs, including the intestine, liver, and mammary gland (van Herwaarden and Schinkel, 2006). Therefore, this protein transporter participates in drug-drug interactions, drug adverse effects, and even drug efficacy (Mealey, 2013; Lee et al., 2015; Robey et al., 2018).

In addition to the drug physicochemical properties related to membrane diffusion, ABCG2 is considered an important factor affecting drug transfer into milk (Ito et al., 2015). Its induced expression in mammary gland during lactation plays an important role in the active secretion into milk of different compounds (Jonker

This work was supported by the Spanish Ministry of Economy and Competitiveness and the European Regional Development Fund (MINECO/ FEDER, UE) [Project AGL2015-65626-R]; the Spanish Ministry of Education, Culture and Sport [Pre-Doctoral Fellowship FPU14/05131] (to D.G.-M.); the Ministry of Economy and Competitiveness [Pre-Doctoral Fellowship BES-2016077235] (to A.M.G.-L.); and the Junta de Castilla y Leon and European Regional Development Fund [Post-Doctoral Fellowship LE011P17] (to I.A.-F.).

https://doi.org/10.1124/dmd.118.085506. et al., 2005) such as antibiotics (Otero et al., 2013, 2016), carcinogens (van Herwaarden and Schinkel, 2006), antiparasitics (Mahnke et al., 2016), and natural compounds (Miguel et al., 2014; García-Mateos et al., 2017), among others.

Genetic variants of ABCG2 can alter the pharmacokinetics and bioavailability of its substrates (Mealey, 2013; Rocha et al., 2018). In the human species, there are some ABCG2 polymorphisms associated with a lower function of this transporter, such as Q141K (Tu et al., 2018) and V12M (Tamura et al., 2012), which are related to diseases and adverse drug effects in the population. In the veterinary field, the bovine ABCG2 Y581S single nucleotide polymorphism is widely spread in the Holstein population (Ron et al., 2006). It is a gain-of-function polymorphism (Merino et al., 2009) that also affects milk production and fat, protein, and lactose content of milk (Cohen-Zinder et al., 2005; Lopdell et al., 2017; Sanchez et al., 2017). Our previous in vitro studies using transduced cell models have revealed differential antimicrobial transport activity depending on the genetic variant (Real et al., 2011). In vivo pharmacokinetic studies with Y/Y homozygous and Y/S heterozygous cows have shown differences in secretion into milk of fluoroquinolones such as danofloxacin, enrofloxacin, and ciprofloxacin between both groups of animals (Otero et al., 2013, 2015, 2016).

Nonsteroidal anti-inflammatory drugs (NSAIDs) are widely used in human and veterinary medicine for their pharmacological effects such as analgesic, anti-inflammatory, and antipyretic actions. These

ABBREVIATIONS: $5 \mathrm{OH}-\mathrm{FLU}, 5$-hydroxyflunixin; $\mathrm{AUC}_{0-\infty}$, area under the curve from zero to infinity; FLU, flunixin; $L O D$, limit of detection; $L O Q$, limit of quantification; MDCK, Madin-Darby canine kidney; NSAID, nonsteroidal anti-inflammatory drug. 
drugs inhibit cyclooxygenase enzymes in the arachidonic acid cascade, which are involved in the biosynthesis of prostaglandins (Landoni et al., 1995; Cheng et al., 1998; Lees et al., 2004).

Flunixin (FLU) is the most important NSAIDs used in cattle (Fajt et al., 2011). It is the only anti-inflammatory agent authorized in the United States for use in milking cows (Food and Drug Administration, 2004) to treat pyrexia and endotoxemia associated with mastitis, and it is one of the few NSAIDs labeled for intravenous route authorized in lactating cows in the European Union (European Medicines Agency, 2000). However, NSAIDs are drugs under regulation in food animals due to the presence of residues that pose a serious risk for consumers (Smith et al., 2008). In the case of FLU therapeutics, 5-hydroxyflunixin (5OH-FLU) was identified as the main FLU metabolite and the marker residue in bovine milk (Feely et al., 2002) with a maximum residue limit of $40 \mu \mathrm{g} / \mathrm{kg}$ established by the European Medicines Agency (2000) and 2 parts per billion by the Food and Drug Administration (2004). In fact, 5OH-FLU levels are higher than FLU levels in cow milk (Feely et al., 2002), probably due in part to their different physicochemical properties and the extensive liver metabolism of FLU. Nevertheless, some studies have shown that alteration of the dose or route of administration, or the presence of disease processes, could affect the presence of violative residues even after withdrawal periods are finished (Kissell et al., 2015; Smith et al., 2015; Shelver et al., 2016).

Therefore, knowledge of the factors affecting the presence of residues of these compounds into milk is relevant for therapeutics and human health. The objective of our study was to investigate the role of ABCG2 in the pharmacokinetics and secretion into milk of FLU and its main metabolite, 5OH-FLU, using Abcg $2^{(-/-)}$mice, and to research the effect of the bovine ABCG2 Y581S polymorphism in FLU and 5OH-FLU plasma and milk levels. Correlation of our in vivo data with in vitro cells studies involving murine Abcg2 and the two bovine ABCG2 variants (Y581 and S581) was also assessed.

\section{Materials and Methods}

Reagents and Chemicals. FLU, 5OH-FLU, diclofenac sodium, niflumic acid, and Lucifer yellow were purchased from Sigma-Aldrich (St. Louis, MO). Ko143 was obtained from Tocris (Bristol, UK). For the pharmacokinetic studies, flunixin meglumine (Finadyne $50 \mathrm{mg} / \mathrm{ml}$ ) was obtained from MSD Animal Health SL (Salamanca, Spain).

Cell Culture. Madin-Darby canine kidney (MDCK) II (epithelial) parental cells and the MDCK-II Abcg2 murine transduced subclone were supplied by Dr. Schinkel (The Netherlands Cancer Institute, Amsterdam, The Netherlands). Generation and characterization of MDCK-II subclones transduced with the Y581 and S581 variants have been reported previously by our research group (Real et al., 2011). Cell culturing was performed as described elsewhere (GonzálezLobato et al., 2014)

Transport Studies. Transepithelial transport assays were carried out as previously described with minor modifications (Pavek et al., 2005; Real et al., 2011) using parental MDCK-II, Abcg2 murine-transduced subclones, and bovine ABCG2-transduced subclones. At the end of the experiment, confluence of the monolayer was checked with Lucifer yellow permeability assays (Oltra-Noguera et al., 2015).

At the beginning of the experiment $(t=0)$ medium was substituted in an apical or basolateral compartment with fresh medium including $20 \mu \mathrm{M}$ of FLU or $10 \mu \mathrm{M}$ of 5OH-FLU, with or without Ko143. Concentrations were chosen based on sensitivity of high-performance liquid chromatography analysis. Hanks' balanced salt solution (Sigma-Aldrich) supplemented with 4-(2-hydroxyethyl)-1-piperazineethanesulfonic acid and $25 \mathrm{mM}$ HEPES (pH 7.4) was used as transport medium. Aliquots of $100 \mu \mathrm{l}$ were sampled each hour up to 4 hours from the opposite compartment and the same volume of culture media was replaced each time. Samples were kept at $-20^{\circ} \mathrm{C}$ until analysis.

Active transport across MDCK-II cells was reported as the relative transport ratio, determined as the concentration permeated toward the apical compartment (basolateral-to-apical transport) divided by the concentration permeated toward the basolateral compartment (apical-to-basolateral transport) at 4 hours.

Animal Experiment. European legislation was applied to animal handling (European Community, 2010). Experimental methods were approved by the Animal Care and Use Committee of University of Leon and Junta de Castilla y Leon (ULE_011_2016 and ULE_002_2017).

Milk Secretion Studies in Mice. Lactating female $\mathrm{Abcg} 2^{(-)}$and wild-type mice $(N=3-7,9-13$ weeks of age) were supplied by Dr. Schinkel (The Netherlands Cancer Institute). They were maintained in an environment controlled for temperature and light/dark cycle.

Pups around 10 days old were removed from their mothers 4 hours before the experiment. For intravenous administration of FLU or $5 \mathrm{OH}-\mathrm{FLU}(4 \mathrm{mg} / \mathrm{kg})$, $150 \mu \mathrm{l}$ of drug solution $/ 30 \mathrm{~g}$ b.wt. was administered into the tail of mice under anesthesia with isoflurane. The drug solution consisted of $10 \%(\mathrm{v} / \mathrm{v})$ Finadyne and $90 \%(\mathrm{v} / \mathrm{v})$ saline solution for the FLU experiments. In the case of 5OH-FLU, the compound was dissolved in $10 \%(\mathrm{v} / \mathrm{v})$ ethanol, $40 \%(\mathrm{v} / \mathrm{v})$ polyethylene glycol 400 , and 50\% saline. Milk and plasma samples were collected using the method reported by Miguel et al. (2014).

Pharmacokinetic Studies on Dairy Cows. Cows were kept on a private farm near Leon, Spain. Twelve lactating Holstein cows weighing $\sim 800 \mathrm{~kg}$ were used. Milk yield was $41.96 \pm 6.67 \mathrm{~kg} / \mathrm{day}$. The Y581S genotypes were determined in accordance with Komisarek and Dorynek (2009). Accordingly, two groups of six Y/Y581 homozygous and six Y/S581 heterozygous cows were defined for experimental design. No differences were found in age, weight, or milk yield between the two sets of cows. Both groups were treated intramuscularly with $2.2 \mathrm{mg} / \mathrm{kg}$ of flunixin meglumine (Finadyne). Blood samples $(5 \mathrm{ml})$ from the tail vein were obtained at 1, 3, 6, 14, 24, 30, and 38 hours after administration. Samples of milk were manually taken at 3 hours and using an automatic milking machine during normal milking at $6,14,24,30,38,48$, and 54 hours. No more sampling points were possible because of the private nature of the farm. Plasma was obtained by centrifugation and samples were kept at $-20^{\circ} \mathrm{C}$ until analysis.

High-Performance Liquid Chromatography Analysis. Determination of concentration of FLU and its main metabolite 5OH-FLU in plasma and milk samples from mouse experiments and samples of transport assays was based on previously published methods (Gallo et al., 2008) with some modifications using diclofenac as an internal standard. Mouse samples were cleaned up using the method described by Odensvik and Johansson (1995) with some modifications. Samples of culture medium were analyzed without processing. A $4 \mu \mathrm{m}$ particle $(250 \times 4.6 \mathrm{~mm}) 80 \AA$ A Synergi column (Phenomenex, Torrance, CA) was used for the chromatographic separation. In transepithelial transport assays, the limit of detection (LOD) and limit of quantification (LOQ) values obtained were 0.01 and $0.03 \mu \mathrm{g} / \mathrm{ml}$ for FLU and 0.008 and $0.02 \mu \mathrm{g} / \mathrm{ml}$ for $5 \mathrm{OH}-\mathrm{FLU}$, respectively.

In the mouse experiments, the LOD and LOQ values obtained for FLU were 0.15 and $0.39 \mu \mathrm{g} / \mathrm{ml}$ in plasma and 0.05 and $0.11 \mu \mathrm{g} / \mathrm{ml}$ in milk, respectively. For $5 \mathrm{OH}-\mathrm{FLU}$, the LOD and LOQ values were 0.05 and $0.12 \mu \mathrm{g} / \mathrm{ml}$ in plasma and 0.03 and $0.07 \mu \mathrm{g} / \mathrm{ml}$ in milk, respectively.

Ultra-Performance Liquid Chromatography Quadrupole Time-of-Flight Mass Spectrometry Analysis. Determination of concentration of FLU and its main metabolite 5OH-FLU in plasma and milk samples from pharmacokinetics studies in dairy cattle were based on previously published methods (Rúbies et al., 2016) with some modifications.

Plasma and milk samples must be processed before injection into the ultraperformance liquid chromatography system following the clean-up method previously described by Kissell et al. (2015) using niflumic acid as an internal standard. Analyses were performed using a Waters ACQuity UPLC H-Class system coupled to an ACQuity TQD tandem quadrupole mass spectrometer (Waters Corporation, Milford, MA). A Phenomenex Kinetex C18 column ( $2.6 \mu \mathrm{m}$, $100 \times 3.00 \mathrm{~mm}$ ) was used for the chromatographic separation. Experiments were performed in positive ion mode at mass-to-charge values of 313, 297, and 283 for 5OH-FLU, FLU, and niflumic acid, respectively. Masslynx software (version 4.1; Waters Corporation) was used for data acquisition and processing.

Plasma LOD was $2.84 \mathrm{ng} / \mathrm{ml}$ for FLU and $4.83 \mathrm{ng} / \mathrm{ml}$ for $5 \mathrm{OH}-\mathrm{FLU}$, whereas the LOQs were 7.67 and $6.68 \mathrm{ng} / \mathrm{ml}$ for FLU and 5OH-FLU, respectively. The milk LODs were 0.17 and $1.42 \mathrm{ng} / \mathrm{ml}$ for FLU and 5OH-FLU and the LOQs were 0.41 and $3.96 \mathrm{ng} / \mathrm{ml}$ for FLU and 5OH-FLU, respectively.

Pharmacokinetic Calculations and Statistical Analysis. The pharmacokinetic parameters were determined as reported elsewhere (Otero et al., 2018). The results are reported as the mean \pm S.D. Normal distributions of data were tested 
by the Shapiro-Wilk test. Data with normal distribution were analyzed by the twotailed Student's test. Data with non-normal distribution were tested using the Mann-Whitney $U$ test. Differences were considered statistically significant when $P<0.05$. Statistical analyses were carried out with the SPSS 24 software (IBM Corporation, Armonk, NY).

\section{Results}

In Vitro Interaction of FLU and Its Main Metabolite with the ABCG2 Transporter. To study the in vitro interaction between ABCG2 and NSAID FLU and its main metabolite 5OH-FLU, transepithelial transport assays were carried out using parental MDCK-II and their subclones transduced with murine and two variants of bovine ABCG2 (Figs. 1 and 2).

In the parental MDCK-II cells, apical-to-basolateral-directed translocation was equal to basolateral-to-apical translocation in FLU and
5OH-FLU assays (Figs. 1A and 2A). We observed basolateral-to-apical preferential transport of FLU and 5OH-FLU in murine Abcg2- and bovine ABCG2-transduced cells compared with the parental cells (Figs. 1, B-D, and 2, B-D). Relative efflux transport ratios at 4 hours were significantly higher for FLU (34.00 \pm 7.44 in murine Abcg2, $1.47 \pm 0.05$ in bABCG2 Y581, and $2.09 \pm 0.33$ in bABCG2 S581) compared with parental cells $(1.08 \pm 0.26 ; P<0.05)$. In the case of $5 \mathrm{OH}-\mathrm{FLU}$, these ratios were also significantly increased $(4.30 \pm 2.69 \mathrm{in}$ murine Abcg2, $2.19 \pm 0.46$ in bABCG2 Y581, and $2.14 \pm 0.65$ in bABCG2 S581) compared with control cells $(0.89 \pm 0.14)(P<0.05)$. When the selective ABCG2 inhibitor Ko143 was added the basolateralto-apical preferential transport was completely reversed in all ABCG2transduced subclones (Figs. 1, E-H, and 2, E-H). Furthermore, in the case of FLU the relative efflux transport ratio was significantly higher in the S581 bovine variant compared with the Y581 variant (Fig. 1, C and D)
A

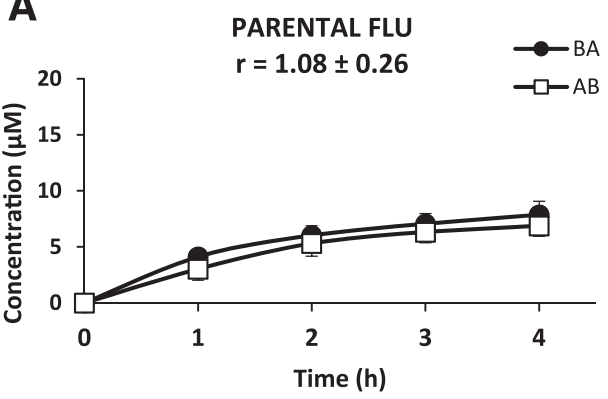

B
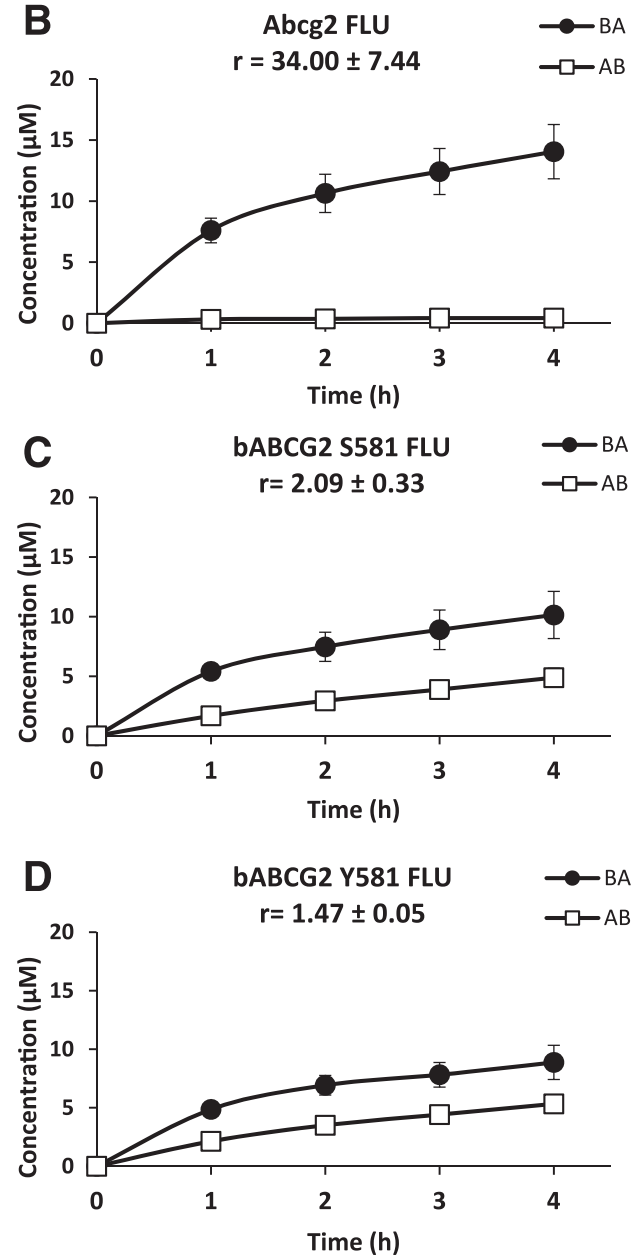

E

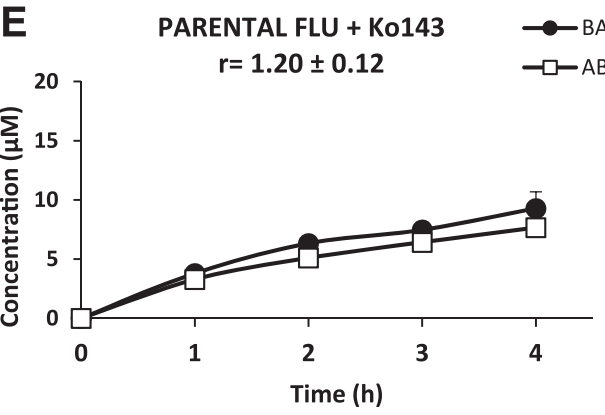

F
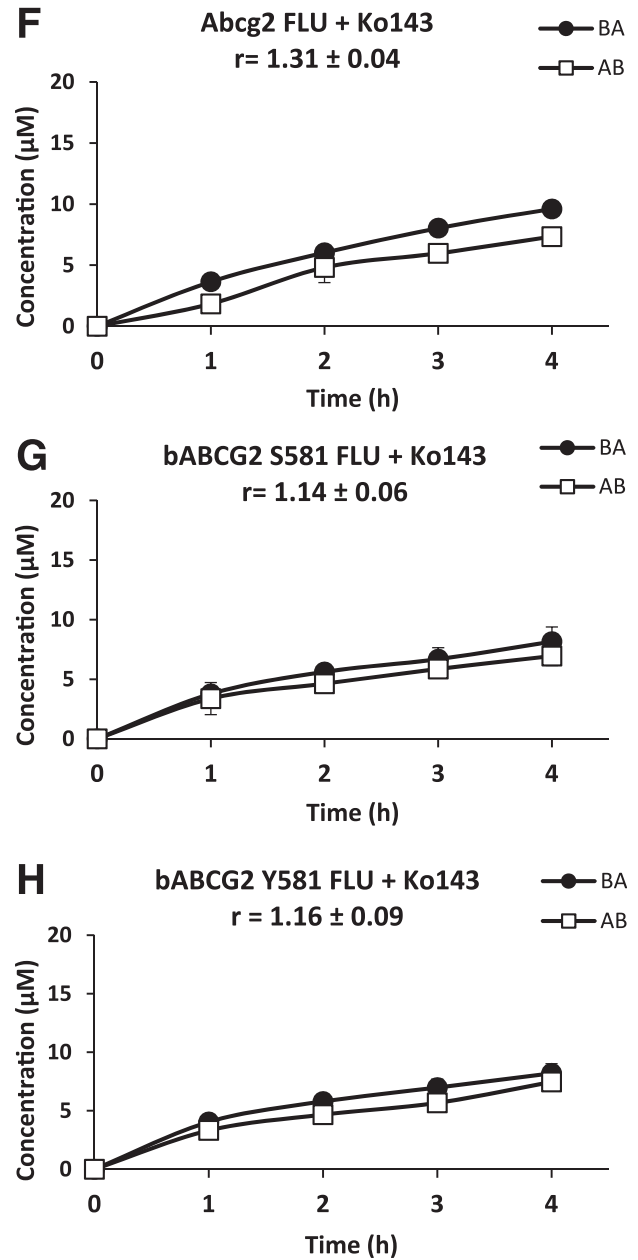

Fig. 1. Transepithelial transport assay of FLU at $20 \mu \mathrm{M}$ in parental MDCK-II cells and its subclones transduced with murine Abcg2 and the two bovine variants (Y581 and S581) in the absence (A-D) or presence $(\mathrm{E}-\mathrm{H})$ of the specific ABCG2 inhibitor Ko143. The experiment was started $(t=0)$ by replacing the medium in either the apical or basolateral compartment with fresh culture medium containing $20 \mu \mathrm{M}$ of FLU. Aliquots of $100 \mu \mathrm{l}$ were taken from the opposite compartment at 1, 2, 3, and 4 hours and concentrations were measured by highperformance liquid chromatography. Concentration permeated toward apical compartment represents basolateral-to-apical transport $(\mathbf{O})$; concentration permeated toward basolateral compartment represents apical-to-basolateral transport ( $\square$ ). Results are represented as mean \pm S.D.; " $r$ " represents relative transport ratio: basolateral-to-apical transport divided by apical-to-basolateral transport at 4 hours $(n=3-6)$. 
A

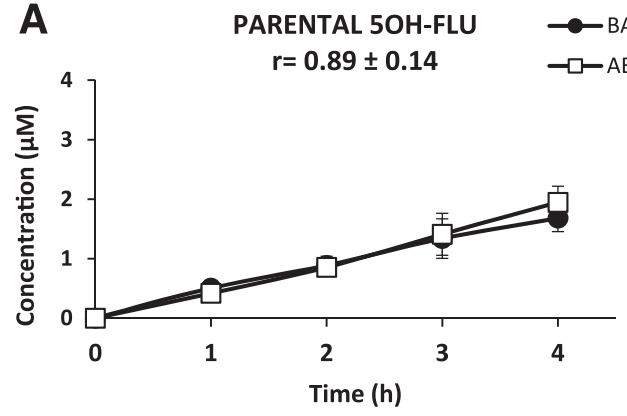

B
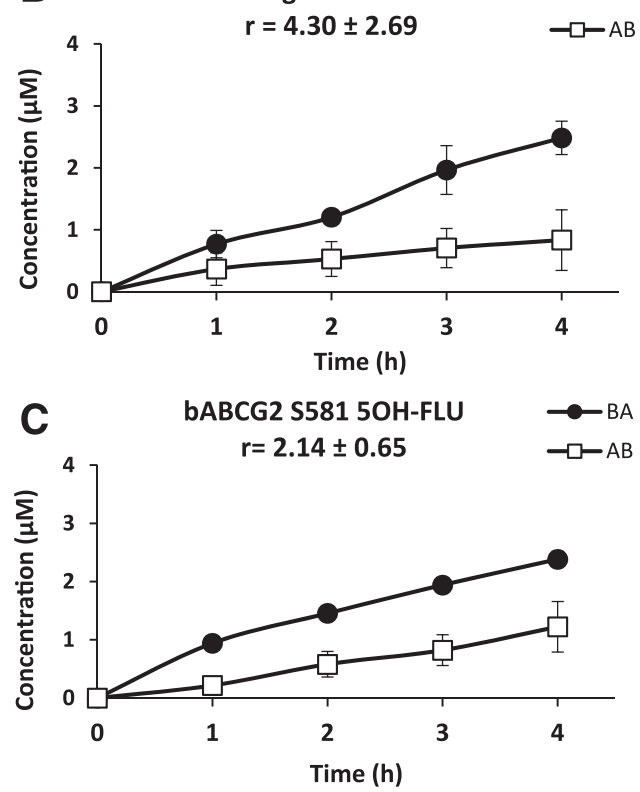

D

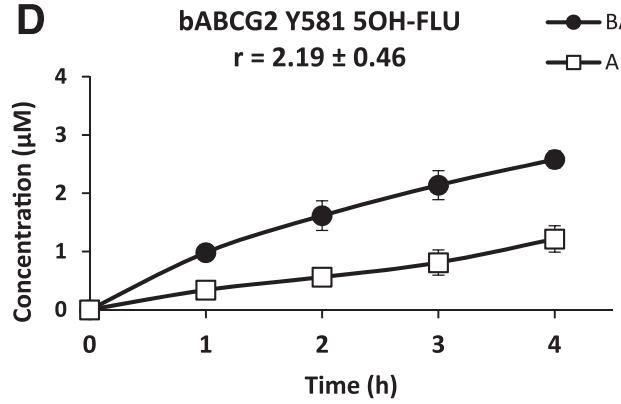

E PARENTAL 5OH-FLU + Ko143 $\underset{r=0.87 \pm 0.22}{\longrightarrow-B A}$

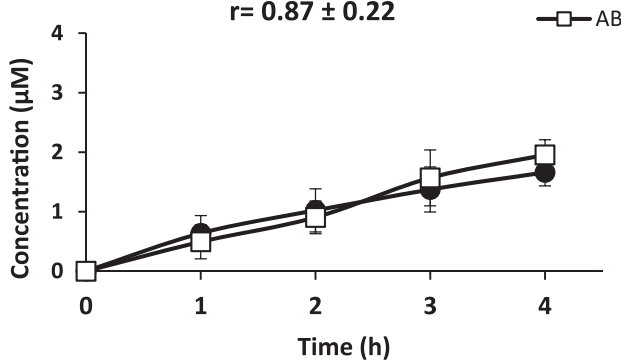

F Abcg2 5OH-FLU + Ko143 $\rightarrow$ BA

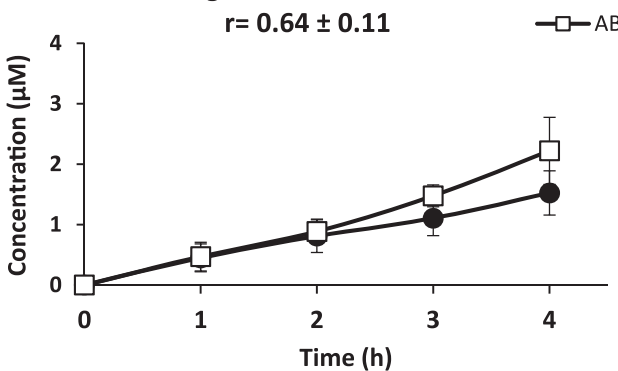

G bABCG2 S581 5OH-FLU + Ko143 $\underset{r=0.96 \pm 0.07}{\rightarrow-B A}$

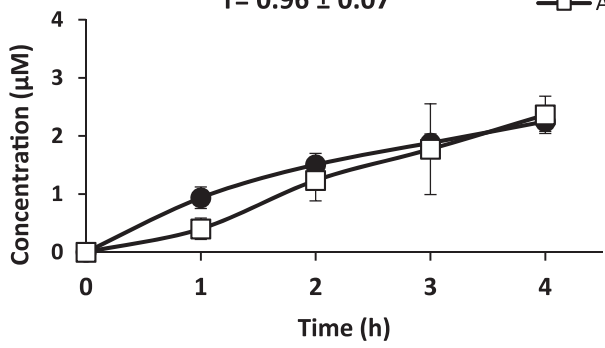

H bABCG2 Y581 5OH-FLU + Ko143 $\rightarrow$ BA

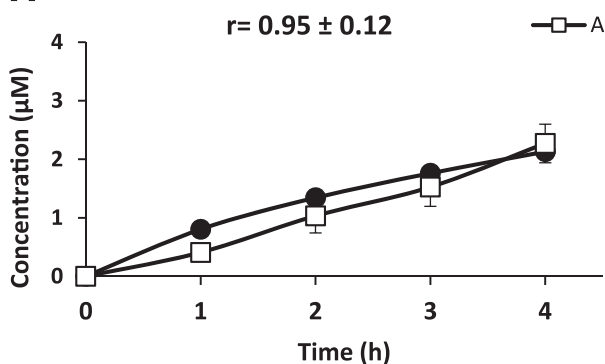

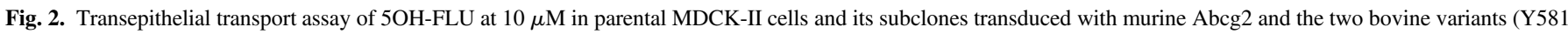

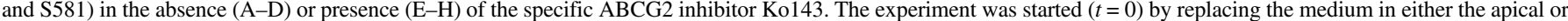

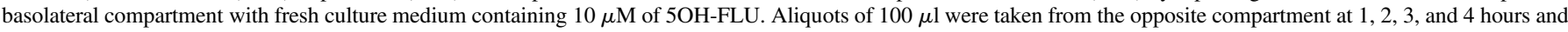

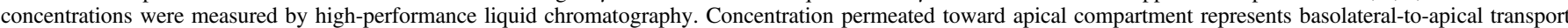

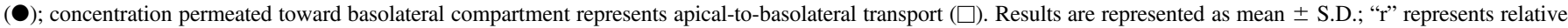
transport ratio: basolateral-to-apical transport divided by apical-to-basolateral transport at 4 hours $(n=3-6)$.

$(2.09 \pm 0.33$ vs. $1.47 \pm 0.05$, respectively; $P<0.05)$, indicating that the S581 variant was more efficient in FLU transport. In contrast to the FLU results, no significant differences between the two bovine ABCG2 variants were found for 5OH-FLU (Fig. 2, C and D).

These results show that murine and bovine ABCG2 play an important role in the active efflux transport of the NSAID FLU and its main metabolite 5OH-FLU. Moreover, FLU is transported more efficiently by the bovine S581 variant compared with the Y581 variant. This difference was not reported for $5 \mathrm{OH}-\mathrm{FLU}$.

Plasma and Milk Levels of FLU and 5OH-FLU in $\operatorname{Abcg2}^{(-/-)}$ Knockout Mice. To study the involvement of Abcg2 in the plasma and milk levels of these compounds, we administered FLU or 5OH-FLU to wild-type and Abcg $2^{(-/-)}$mice (Fig. 3). No 5OH-FLU was detected in plasma and milk after FLU administration. No significant differences were observed in the plasma concentration of FLU and 5OH-FLU after treatment in wild-type and $\mathrm{Abcg} 2^{(-1-)}$ mice. However, milk concentrations were more than 2.5-fold higher in wild-type mice compared with Abcg $2^{(-/-)}$mice for FLU $(1.85 \pm 0.29 \mu \mathrm{g} / \mathrm{ml}$ vs. $0.72 \pm 0.18 \mu \mathrm{g} / \mathrm{ml}$; $P<0.01)$ and approximately 8 -fold higher in wild-type compared with Abcg $2^{(-l-)}$ mice for $5 \mathrm{OH}-\mathrm{FLU}(1.82 \pm 0.90 \mu \mathrm{g} / \mathrm{ml}$ vs. $0.23 \pm 0.17 \mu \mathrm{g} / \mathrm{ml}$; $P<0.01)$. The milk-to-plasma ratio of FLU in wild-type mice was more than 3-fold higher than in $\mathrm{Abcg} 2^{(-/-)}$mice $(0.43 \pm 0.17$ vs. $0.14 \pm 0.02$; 

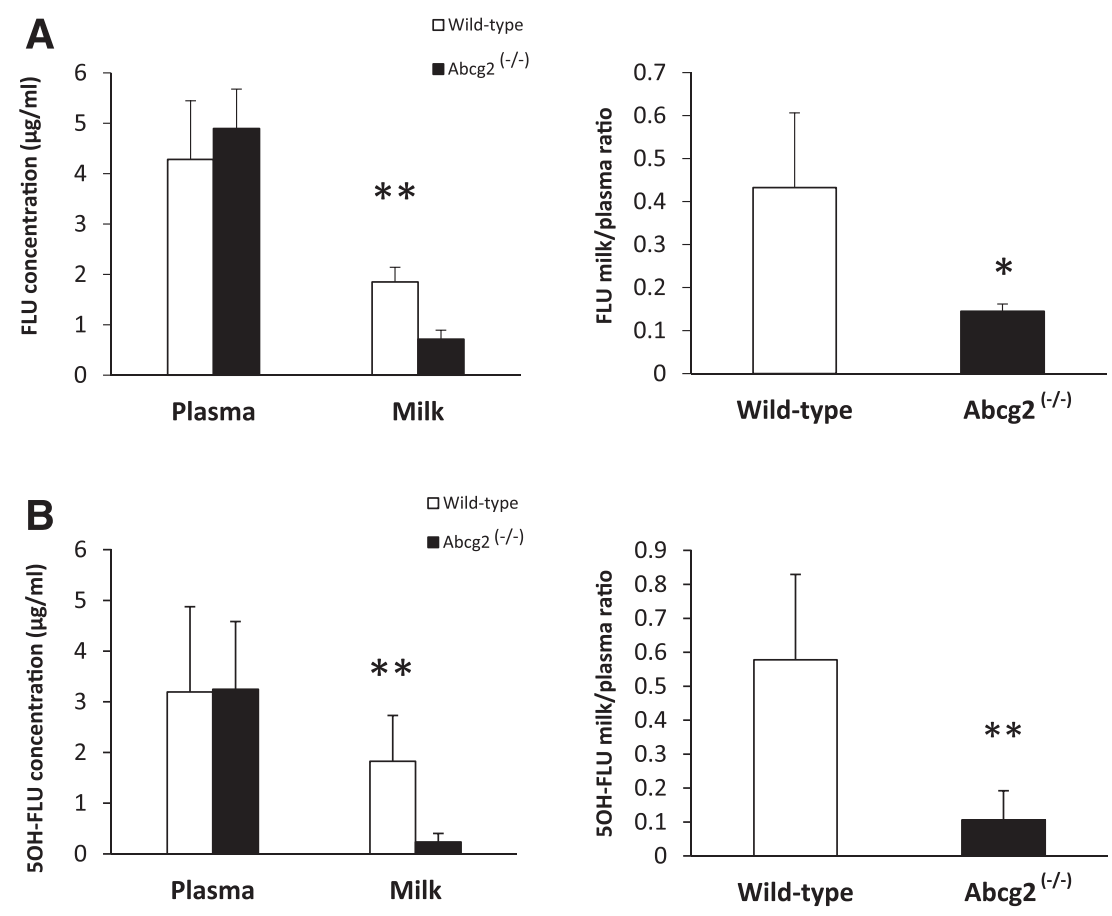

Fig. 3. Plasma and milk concentration and milk-to-plasma ratio of FLU (A) and 5OH-FLU (B) in Abcg $2^{(-/-)}$mice after intravenous administration at a dose of $4 \mathrm{mg} / \mathrm{kg}$ b.wt. Plasma and milk were collected 40 minutes after administration of FLU and 20 minutes after 5OH-FLU treatment. Milk and plasma levels were determined by high-performance liquid chromatography. Results are mean \pm S.D.; $* P<0.05$ and $* * P<0.01$ represent significant differences between both groups of mice $(n=3-6)$.

$P<0.05)$. In the case of 5OH-FLU, the milk-to-plasma ratio was 5-fold higher in wild-type compared with $\mathrm{Abcg} 2^{(-/-)}$lactating mice $(0.58 \pm$ 0.25 vs. $0.11 \pm 0.08 ; P<0.01)$. Our results clearly show that Abcg2 plays an important role in the active secretion into milk of FLU and 5OH-FLU.

Plasma Pharmacokinetics and Secretion into Milk of FLU and 5OH-FLU in Dairy Cows Carrying the Y581S Polymorphism. The effect of the Y581S polymorphism on plasma levels and secretion into milk of the NSAID FLU and its main metabolite 5OH-FLU was studied using Y/Y581 homozygous and Y/S581 heterozygous lactating cows (Figs. 4 and 5), after the administration of a single dose of Finadyne at $2.2 \mathrm{mg} / \mathrm{kg}$ b.wt. by intramuscular administration. The plasma profile was dominated by the parental drug FLU. No significant differences in the plasma levels (Fig. 4) and plasma pharmacokinetics parameters (Table 1) were observed between the two groups of animals.

The milk profile was dominated by 5OH-FLU (Fig. 5). No significant differences were obtained in the milk levels and milk pharmacokinetics parameters for $5 \mathrm{OH}-\mathrm{FLU}$ between the two groups of cows. Only the half-life was significantly different (Table 2). However, significant differences for the secretion of FLU into milk between both groups of animals were shown (Fig. 4). The milk levels for FLU were significantly higher for Y/S581 compared with Y/Y581 animals at 6,14 , and 24 hours $(P<0.05)$. In addition, the area under the curve from zero to infinity $\left(\mathrm{AUC}_{0-\infty}\right)$ and $C_{\max }$ values were approximately 1.5-fold higher in Y/S581 animals than in Y/Y581 animals $\left(104.67 \pm 25.86\right.$ vs. $69.53 \pm 9.61 \mathrm{ng} \cdot \mathrm{h} / \mathrm{ml}$ for $\mathrm{AUC}_{0-\infty}$ and

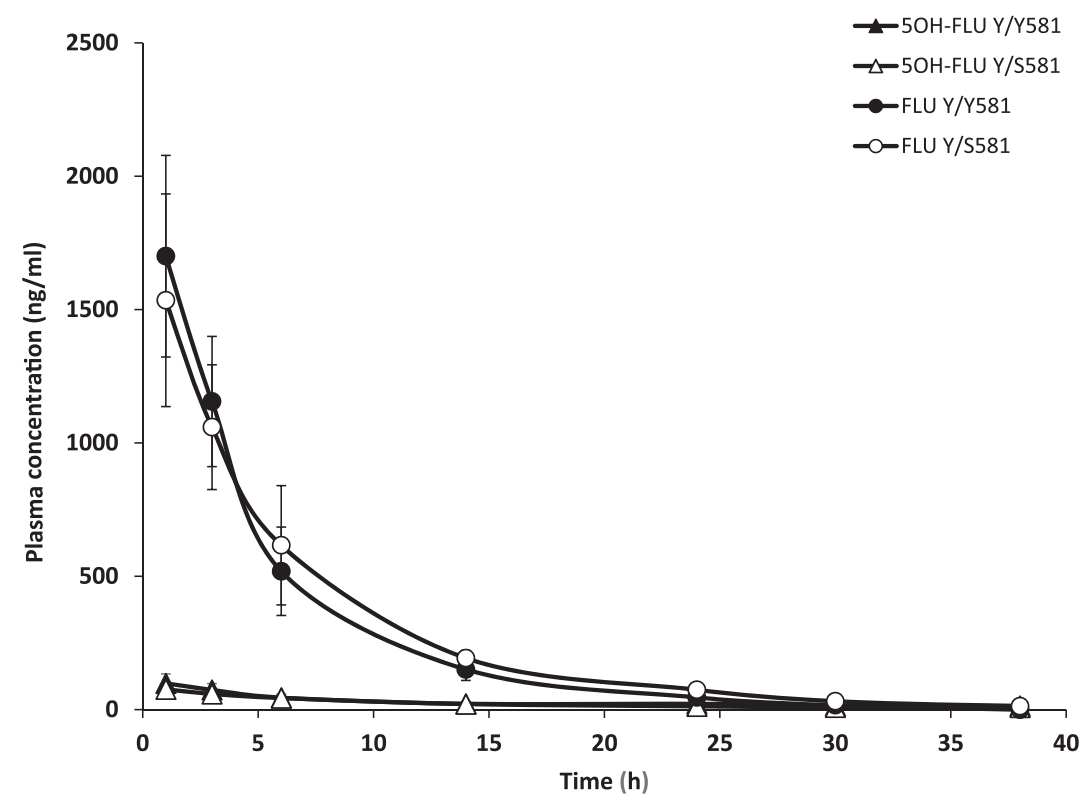

Fig. 4. Plasma concentration of FLU and 5OH-FLU after intramuscular administration of a single dose of Finadyne at $2.2 \mathrm{mg} / \mathrm{kg}$ b.wt. to Y/Y581 homozygous and Y/S581 heterozygous lactating cows. Plasma samples were collected at various times over 38 hours. Plasma levels were determined by ultraperformance liquid chromatography tandem mass spectrometry. The results are presented as mean \pm S.D. $(n=6)$. 


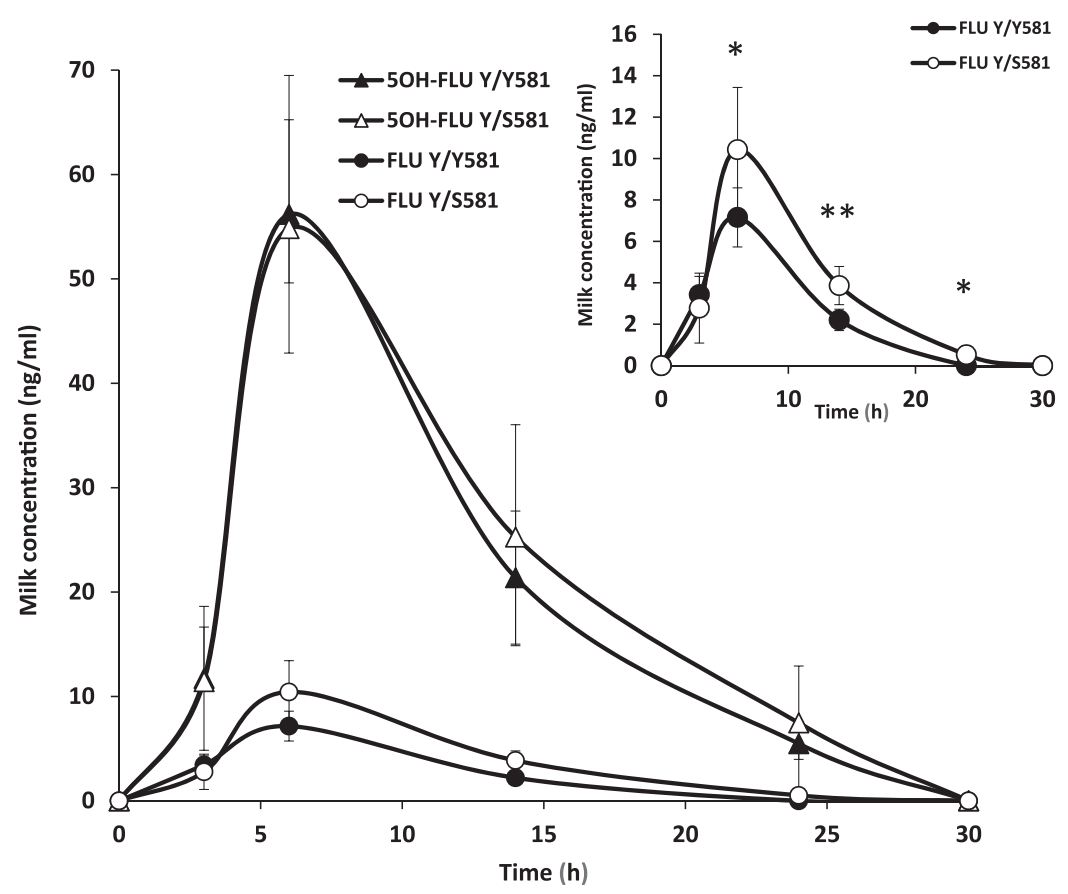

Fig. 5. Milk concentration of FLU and 5OH-FLU after intramuscular administration of a single dose of Finadyne at $2.2 \mathrm{mg} / \mathrm{kg}$ b.wt. to Y/Y581 homozygous and Y/S581 heterozygous lactating cows. Milk samples were collected at various times over 54 hours. Milk levels were determined by ultra-performance liquid chromatography tandem mass spectrometry. Concentrations from 30 hours were undetectable. The inset shows FLU concentrations alone. The results are presented as mean \pm S.D. $(n=6) ; * P<0.05$ and $* * P<0.01$ represent significant differences between both groups of cows.

$10.42 \pm 2.99$ vs. $7.15 \pm 1.43 \mathrm{ng} / \mathrm{ml}$ for $C_{\max }$ ) (Table 2 ). The mean residence time was around 1.2-fold higher in cows carrying the Y581S polymorphism $(P<0.05 ; 9.15 \pm 0.88$ vs. $7.82 \pm 0.52$ hours $)$ (Table 2). In addition, significant differences were observed between the two groups in $\mathrm{AUC}_{0-\infty}$ milk-to-plasma ratios for FLU.

Our results show that the bovine Y581S ABCG2 polymorphism increases the milk secretion of the parental compound FLU in dairy cattle; however, it does not affect secretion of 5OH-FLU into milk.

\section{Discussion}

Several pharmacokinetics and residue research studies and surveys have been previously undertaken with FLU and 5OH-FLU on different farm species such as dairy cows (Jedziniak et al., 2009, 2013; Deyrup et al., 2012; Kissell et al., 2012, 2013, 2015), sheep (Marini et al., 2016), and goats (Königsson et al., 2003). However, this is the first study to explore the in vivo role of the ABCG2 transporter in these processes for an anti-inflammatory drug in farm animals.

The use of knockout mice as a first step in the study of in vivo interaction with drug transporters has been validated (Giacomini et al., 2010), and it is a widely used model to test the in vivo relevance of some transporters such as P-glycoprotein or ABCG2 in drug pharmacokinetics and secretion into milk (Vlaming et al., 2009). Therefore, as a preclinical setup, our results with knockout mice show that Abcg2 is implicated in the secretion of FLU and 5OH-FLU into milk with higher secretion in wild-type mice than in $\operatorname{Abcg} 2^{(-/-)}$mice (Fig. 3). The effect of compensatory changes in the expression of proteins that participate in metabolism in the $\mathrm{Abcg} 2^{(-1-)}$ mice cannot be completely excluded. However, evidence of such problematic effects in previous studies has never been shown.

With this outcome, we have added the anti-inflammatory FLU and its main metabolite 5OH-FLU to the list of compounds with Abcg2mediated secretion into milk. These results are in accordance with our in vitro findings, which report that FLU and 5OH-FLU were also effectively transported by murine and bovine ABCG2 (Figs. 1 and 2). The very high relative transport ratio in the case of murine Abcg2mediated transport of FLU is noteworthy $(34.00 \pm 7.44)$. All these data suggest that $\mathrm{ABCG} 2$ active transport is involved in the secretion of these compounds into milk.

Regarding the effect of the bovine Y581S ABCG2 polymorphism in the secretion into milk of these compounds, a pharmacokinetic study using cows carrying this polymorphism was designed. Our results confirmed that the predominant compound detected in plasma was FLU (Odensvik and Johansson, 1995; Jedziniak et al., 2007; Kissell et al., 2015). The plasma pharmacokinetics parameters (Table 1) in both groups of lactating cows were similar to those obtained in previous studies in dairy cattle (Rantala et al., 2002; Jedziniak et al., 2007). However, no significant differences in both groups of animals were

TABLE 1

Plasma pharmacokinetic parameters (mean \pm S.D.) in Y/Y581 homozygous and Y/S581 heterozygous dairy cows after administration of a single dose of Finadyne at $2.2 \mathrm{mg} / \mathrm{kg}(n=6)$

\begin{tabular}{|c|c|c|c|c|}
\hline \multirow{2}{*}{ Pharmacokinetic Parameter } & \multicolumn{2}{|c|}{ 5OH-FLU } & \multicolumn{2}{|c|}{ FLU } \\
\hline & Y/Y581 & Y/S581 & Y/Y581 & Y/S581 \\
\hline $\operatorname{AUC}_{0-\infty}(\mathrm{ng} \cdot \mathrm{h} / \mathrm{ml})$ & $1396.3 \pm 445.2$ & $1039.3 \pm 307.3$ & $10,949.3 \pm 2133.3$ & $11,815.0 \pm 2018.0$ \\
\hline$C_{\max }(\mathrm{ng} / \mathrm{ml})$ & $79.25 \pm 25.14$ & $70.33 \pm 14.06$ & $1600.7 \pm 330.4$ & $1494.6 \pm 359.2$ \\
\hline$T_{\max }(\mathrm{h})$ & $1.00 \pm 0.00$ & $1.33 \pm 0.82$ & $1.00 \pm 0.00$ & $1.33 \pm 0.82$ \\
\hline$T_{1 / 2 \text { el }}(\mathrm{h})$ & $12.20 \pm 4.04$ & $9.60 \pm 1.60$ & $4.60 \pm 0.37$ & $5.49 \pm 1.06$ \\
\hline MRT (h) & $19.98 \pm 5.12$ & $14.98 \pm 3.98$ & $5.55 \pm 0.80$ & $7.13 \pm 1.78$ \\
\hline
\end{tabular}

AUC, area under the curve; MRT, mean residence time; $T_{1 / 2}$ el, elimination half-life.; $T_{\max }$, time to maximum concentration. 
TABLE 2

Milk pharmacokinetic parameters (mean \pm S.D.) in Y/Y581 homozygous and Y/S581 heterozygous dairy cows after administration of a single dose of Finadyne at $2.2 \mathrm{mg} / \mathrm{kg}(n=6)$

\begin{tabular}{|c|c|c|c|c|}
\hline \multirow{2}{*}{ Pharmacokinetic Parameter } & \multicolumn{2}{|c|}{ 5OH-FLU } & \multicolumn{2}{|c|}{ FLU } \\
\hline & Y/Y581 & Y/S581 & Y/Y581 & Y/S581 \\
\hline $\operatorname{AUC}_{0-\infty}(\mathrm{ng} \cdot \mathrm{h} / \mathrm{ml})$ & $585.0 \pm 134.4$ & $645.2 \pm 202.4$ & $69.53 \pm 9.61$ & $104.7 \pm 25.86^{*}$ \\
\hline$C_{\max }(\mathrm{ng} / \mathrm{ml})$ & $56.10 \pm 13.39$ & $54.83 \pm 10.40$ & $7.15 \pm 1.43$ & $10.42 \pm 2.99^{*}$ \\
\hline$T_{\max }(\mathrm{h})$ & $6.00 \pm 0.00$ & $6.00 \pm 0.00$ & $6.00 \pm 0.00$ & $6.00 \pm 0.00$ \\
\hline$T_{1 / 2 \text { el }}(\mathrm{h})$ & $5.42 \pm 0.63$ & $6.59 \pm 1.03^{*}$ & $4.80 \pm 0.84$ & $4.98 \pm 0.82$ \\
\hline MRT (h) & $9.97 \pm 0.81$ & $10.78 \pm 1.81$ & $7.82 \pm 0.52$ & $9.15 \pm 0.88^{* *}$ \\
\hline AUC milk/plasma & $0.450 \pm 0.168$ & $0.684 \pm 0.319$ & $0.007 \pm 0.001$ & $0.009 \pm 0.002 *$ \\
\hline
\end{tabular}

AUC, area under the curve; MRT, mean residence time; $T_{1 / 2}$ el, elimination half-life.; $T_{\max }$, time to maximum concentration.

$* P<0.05 ; * * P<0.01$, significantly different from the Y/Y581 group.

obtained for FLU and 5OH-FLU in the plasma levels and pharmacokinetics parameters (Fig. 4; Table 1).

Moreover, our data regarding milk levels are in good agreement with previous publications that describe $5 \mathrm{OH}-\mathrm{FLU}$ as the main FLU metabolite presented into milk (Feely et al., 2002; Daeseleire et al., 2003; Ngoh et al., 2003; Kissell et al., 2012, 2015; Jedziniak et al., 2013). A large amount of 5OH-FLU appeared rapidly in cow milk following administration of FLU. 5OH-FLU milk levels presented a fast rate of elimination after 24 hours of treatment (Ngoh et al., 2003; Jedziniak et al., 2009, 2013; Kissell et al., 2012, 2015). This decrease is more pronounced in the intravenous route than in other routes (Kissell et al., 2012). We obtained significant differences between both groups of cows in milk secretion of the parental drug FLU at 6, 14, and 24 hours post-treatment and in its milk pharmacokinetics parameters $C_{\max }$ and $\mathrm{AUC}_{0-\infty}$, with 1.5-fold higher levels in cows carrying the polymorphism than in noncarrier animals (Fig. 5; Table 2). In addition, the mean residence time elimination parameter significantly increased in the Y/S581 heterozygous animals compared with the Y/Y581 homozygous animals. These results suggest that milk levels of FLU were higher in the Y/S581 animals and that drug persistence in the milk may be longer, indicating that higher concentrations of this NSAID are secreted in the Y/S581 animals for a longer period of time. These results are in good agreement with previous studies by our group in which we demonstrated higher secretion into milk of several antibiotics such as danofloxacin, ciprofloxacin, and enrofloxacin by cows carrying the Y581S polymorphism (Otero et al., 2013, 2015, 2016). However, this is the first time that such an effect has been observed for an anti-inflammatory drug. This contrasts with our results in plasma where no effect of the Y581S polymorphism was observed, probably due to the potential influence of several additional mechanisms at the systemic level. In fact, Miyazaki et al. (2001) and Horii et al. (2004) reported that the OATP-2 active membrane transporter was involved in the bioavailability and biodisposition of FLU in rabbits and cats. However, ABCG2 is the only ATPbinding cassette transporter induced in the mammary gland during lactation (Jonker et al., 2005). Organic cation transporters have also been related to drug transfer in mice (Ito et al., 2014). Otero et al. (2013) also reported that no significant differences were found in plasma levels between Y/Y581 and Y/S581 cows after danofloxacin administration at $1.25 \mathrm{mg} / \mathrm{kg}$ b.wt., although these authors observed higher milk secretion of this antimicrobial in cows carrying the Y581S polymorphism than in noncarriers.

The difference observed between the two bovine genotypes regarding secretion of FLU into milk is in agreement with our in vitro data, where significant differences in the relative transport ratio of FLU at 4 hours were found between cells transduced with Y581 and S581 variants, with higher apically directed transport in the polymorphic variant (Fig. 1, $\mathrm{C}$ and $\mathrm{D})$. However, no differences in the basolateral-to-apical transport of 5OH-FLU between the two bovine ABCG2 variants were observed (Fig. 2, C and D), which is in agreement with the lack of difference in the secretion of $5 \mathrm{OH}-\mathrm{FLU}$ into milk between the two groups of cows (Fig. 5). All these data indicate that in vitro studies using MDCK-II cells are strong and useful tools to research and predict in vivo results. Previous studies have reported the use of in vitro systems for prediction and monitoring of the concentration of drug residues in ruminant milk mediated by ABCG2 (Real et al., 2011; Wassermann et al., 2013; González-Lobato et al., 2014).

Our results show that ABCG2 is implicated in the secretion of FLU and 5OH-FLU into milk. This knowledge will help to understand and manage the presence of anti-inflammatory drugs and their metabolite residues in milk. To the best of our knowledge, although there is no available information about the pharmacological activity of 5-OH-FLU, food residues of these compounds are deemed a potential risk to consumers and maximum residue limits for them in food products of animal origin, including milk, have been established (European Medicines Agency, 2000; Food and Drug Administration, 2004).

Apart from the genetic Y581S polymorphism, several factors influence the activity of ABCG2, including gender, diet compounds, and coadministration with drugs that interact with the transporter. In fact, ABCG2-mediated secretion of drugs into milk can be greatly diminished by administration of ABCG2 inhibitors present in the diet such as flavonoids or lignans. This effect has been shown with ABCG2 substrates such as fluoroquinolones and nitrofurantoin in ruminants. This antimicrobial secretion into milk was decreased using flavonoids (soy-enriched diet) or lignans (flaxseed-enriched diet) (Pulido et al., 2006; Perez et al., 2013; Otero et al., 2018). Regarding drug modulation of milk residues, the milk secretion of the antimicrobial danofloxacin was reduced by coadministration of the macrocyclic lactone ivermectin, an ABCG2 inhibitor (Real et al., 2011). Moreover, the coadministration of the anthelmintic triclabendazole, another ABCG2 inhibitor, with moxidectin reduced milk levels of this macrocyclic lactone (Barrera et al., 2013). Therefore, active transport of FLU and its main metabolite into milk by ABCG2 may have implications in the coadministration of FLU with other drugs or natural feed components that also interact with ABCG2 in the treatment of dairy cows because it may affect milk levels of drug residues with an important health risk for human consumption.

Our findings are a new step toward the identification of factors that alter drug exposure in livestock and are involved in interindividual variability. This newly discovered factor involved in interindividual disposition variability of anti-inflammatory drugs could potentially affect treatment efficacy and contribute to milk residues.

In conclusion, we demonstrate that ABCG2 is involved in the secretion into milk of FLU and 5OH-FLU and that the bovine Y581S variant increases the levels of FLU in milk but does not affect 5OH-FLU 
milk levels. Furthermore, our results obtained from the pharmacokinetics and milk secretion studies with mice and dairy cattle are in agreement with our in vitro assays.

\section{Acknowledgments}

We thank Dr. A.H. Schinkel (The Netherlands Cancer Institute, Amsterdam, The Netherlands), who provided parental MDCKII cells its murine Abcg2transduced subclones. The authors thank Virginia Medina (Laboratorio de Tecnicas Instrumentales, University of Leon) for technical assistance and support. We thank James McCue for help in language editing.

\section{Authorship Contributions}

Participated in research design: Garcia-Mateos, Alvarez, Merino.

Conducted experiments: Garcia-Mateos, Garcia-Lino, Alvarez-Fernandez, Blanco-Paniagua, de la Fuente.

Performed data analysis: Garcia-Mateos, Merino.

Wrote or contributed to the writing of the manuscript: Garcia-Mateos, Alvarez, Merino.

\section{References}

Barrera B, González-Lobato L, Otero JA, Real R, Prieto JG, Álvarez AI, and Merino G (2013) Effects of triclabendazole on secretion of danofloxacin and moxidectin into the milk of sheep: role of triclabendazole metabolites as inhibitors of the ruminant ABCG2 transporter. Vet J 198: 429-436.

Cheng Z, Nolan AM, and McKellar QA (1998) Measurement of cyclooxygenase inhibition in vivo: a study of two non-steroidal anti-inflammatory drugs in sheep. Inflammation 22:353-366.

Cohen-Zinder M, Seroussi E, Larkin DM, Loor JJ, Everts-van der Wind A, Lee JH, Drackley JK, Band MR, Hernandez AG, Shani M, et al. (2005) Identification of a missense mutation in the bovine $A B C G 2$ gene with a major effect on the QTL on chromosome 6 affecting milk yield and composition in Holstein cattle. Genome Res 15:936-944.

Daeseleire E, Mortier L, De Ruyck H, and Geerts N (2003) Determination of flunixin and ketoprofen in milk by liquid chromatography-tandem mass spectrometry. Anal Chim Acta 488:25-34.

Deyrup CL, Southern KJ, Cornett JA, Shultz CE, and Cera DA (2012) Examining the occurrence of residues of flunixin meglumine in cull dairy cows by use of the flunixin cull cow survey. $J \mathrm{Am}$ Vet Med Assoc 241:249-253.

European Community (2010) Directive 2010/63/EU of the European Parliament and of the Council of 22 September 2010 on the protection of animal used for scientific purposes. Official Journal of the European Union. L276:33-79.

European Medicines Agency (2000) Committee for veterinary medicinal products flunixin summary report (I). pp. 18-21.

Fajt VR, Wagner SA, and Norby B (2011) Analgesic drug administration and attitudes about analgesia in cattle among bovine practitioners in the United States. J Am Vet Med Assoc 238: 755-767.

Feely WF, Chester-Yansen C, Thompson K, Campbell JW, Boner PL, Liu DDW, and Crouch LS (2002) Flunixin residues in milk after intravenous treatment of dairy cattle with ${ }^{14} \mathrm{C}$-flunixin. $J$ Agric Food Chem 50:7308-7313.

Food and Drug Administration (2004) Supplemental new animal drug application NADA 101-479 Banamine injectable solution (Flunixin meglumine). pp. 1-20.

Gallo P, Fabbrocino S, Vinci F, Fiori M, Danese V, and Serpe L (2008) Confirmatory identification of sixteen non-steroidal anti-inflammatory drug residues in raw milk by liquid chromatography coupled with ion trap mass spectrometry. Rapid Commun Mass Spectrom 22:841-854.

García-Mateos D, García-Villalba R, Marañón JA, Espín JC, Merino G, and Álvarez AI (2017) The breast cancer resistance protein (BCRP/ABCG2) influences the levels of enterolignans and their metabolites in plasma, milk and mammary gland. $J$ Funct Foods 35:648-654

Giacomini KM, Huang SM, Tweedie DJ, Benet LZ, Brouwer KLR, Chu X, Dahlin A, Evers R, Fischer V, Hillgren KM, et al.; International Transporter Consortium (2010) Membrane transporters in drug development. Nat Rev Drug Discov 9:215-236.

González-Lobato L, Real R, Herrero D, de la Fuente A. Prieto JG, Marqués MM, Álvarez AI, and Merino G (2014) Novel in vitro systems for prediction of veterinary drug residues in ovine milk and dairy products. Food Addit Contam Part A Chem Anal Control Expo Risk Assess 31: $1026-1037$.

Horii Y, Ikenaga M, Shimoda M, and Kokue E (2004) Pharmacokinetics of flunixin in the cat: enterohepatic circulation and active transport mechanism in the liver. $J$ Vet Pharmacol Ther 27: $65-69$.

Ito N, Ito K, Ikebuchi Y, Kito T, Miyata H, Toyoda Y, Takada T, Hisaka A, Honma M, Oka A, et al. (2014) Organic cation transporter/solute carrier family 22a is involved in drug transfer into milk in mice. J Pharm Sci 103:3342-3348.

Ito N, Ito K, Ikebuchi Y, Toyoda Y, Takada T, Hisaka A, Oka A, and Suzuki H (2015) Prediction of drug transfer into milk considering breast cancer resistance protein (BCRP)-mediated transport. Pharm Res 32:2527-2537.

Jedziniak P, Olejnik M, Szprengier-Juszkiewicz T, Smulski S, Kaczmarowski M, and Żmudzki J (2013) Identification of flunixin glucuronide and depletion of flunixin and its marker residue in bovine milk. J Vet Pharmacol Ther 36:571-575.

Jedziniak P, Szprengier-Juszkiewicz T, and Olejnik M (2009) In-house reference materials: 5-hydroxyflunixin and meloxicam in cow milk-preparation and evaluation. Anal Chim Acta 637 346-350.

Jedziniak P, Szprengier-Juszkiewicz T, Olejnik M, and Jaroszewski J (2007) Determination of flunixin and 5-hydroxyflunixin in bovine plasma with HPLC-UV-method development, validation and verification. Bull Vet Inst Pulawy 51:261-266.

Jonker JW, Merino G, Musters S, van Herwaarden AE, Bolscher E, Wagenaar E, Mesman E, Dale TC, and Schinkel AH (2005) The breast cancer resistance protein BCRP (ABCG2) concentrates drugs and carcinogenic xenotoxins into milk. Nat Med 11:127-129.
Kissell LW, Baynes RE, Riviere JE, and Smith GW (2013) Occurrence of flunixin residues in bovine milk samples from the USA. Food Addit Contam Part A Chem Anal Control Expo Risk Assess 30:1513-1516.

Kissell LW, Leavens TL, Baynes RE, Riviere JE, and Smith GW (2015) Comparison of pharmacokinetics and milk elimination of flunixin in healthy cows and cows with mastitis. $J$ Am Vet Med Assoc 246:118-125.

Kissell LW, Smith GW, Leavens TL, Baynes RE, Wu H, and Riviere JE (2012) Plasma pharmacokinetics and milk residues of flunixin and 5-hydroxy flunixin following different routes of administration in dairy cattle. $J$ Dairy Sci 95:7151-7157.

Komisarek J and Dorynek Z (2009) Effect of ABCG2, PPARGCIA, OLRI and SCDI gene polymorphism on estimated breeding values for functional and production traits in Polish Holstein-Friesian bulls. J Appl Genet 50:125-132.

Königsson K, Törneke K, Engeland IV, Odensvik K, and Kindahl H (2003) Pharmacokinetics and pharmacodynamic effects of flunixin after intravenous, intramuscular and oral administration to dairy goats. Acta Vet Scand 44:153-159.

Landoni MF, Cunningham FM, and Lees P (1995) Determination of pharmacokinetics and pharmacodynamics of flunixin in calves by use of pharmacokinetic/pharmacodynamic modeling. $\mathrm{Am}$ $J$ Vet Res 56:786-794.

Lee CA, O'Connor MA, Ritchie TK, Galetin A, Cook JA, Ragueneau-Majlessi I, Ellens H, Feng B, Taub ME, Paine MF, et al. (2015) Breast cancer resistance protein (ABCG2) in clinical pharmacokinetics and drug interactions: practical recommendations for clinical victim and perpetrator drug-drug interaction study design. Drug Metab Dispos 43:490-509.

Lees P, Giraudel J, Landoni MF, and Toutain PL (2004) PK-PD integration and PK-PD modelling of nonsteroidal anti-inflammatory drugs: principles and applications in veterinary pharmacology. $J$ Vet Pharmacol Ther 27:491-502.

Lopdell TJ, Tiplady K, Struchalin M, Johnson TJJ, Keehan M, Sherlock R, Couldrey C, Davis SR, Snell RG, Spelman RJ, et al. (2017) DNA and RNA-sequence based GWAS highlights membrane-transport genes as key modulators of milk lactose content. BMC Genomics 18:968.

Mahnke H, Ballent M, Baumann S, Imperiale F, von Bergen M, Lanusse C, Lifschitz AL, Honsch W, and Halwachs S (2016) The ABCG2 efflux transporter in the mammary gland mediates veterinary drug secretion across the blood-milk barrier into milk of dairy cows. Drug Metab Dispos 44:700-708

Marini D, Pippia J, Colditz IG, Hinch GN, Petherick CJ, and Lee C (2016) Palatability and pharmacokinetics of flunixin when administered to sheep through feed. PeerJ 4:e1800.

Mealey KL (2013) Adverse drug reactions in veterinary patients associated with drug transporters. Vet Clin North Am Small Anim Pract 43:1067-1078.

Merino G, Real R, Baro MF, Gonzalez-Lobato L, Prieto JG, Alvarez AI, and Marques MM (2009) Natural allelic variants of bovine ATP-binding cassette transporter ABCG2: increased activity of the Ser581 variant and development of tools for the discovery of new ABCG2 inhibitors. Drug Metab Dispos 37:5-9.

Miguel V, Otero JA, García-Villalba R, Tomás-Barberán F, Espín JC, Merino G, and Álvarez A (2014) Role of ABCG2 in transport of the mammalian lignan enterolactone and its secretion into milk in Abcg2 knockout mice. Drug Metab Dispos 42:943-946.

Miyazaki Y, Horii Y, Ikenaga N, Shimoda M, and Kokue E (2001) Possible active transport mechanism in pharmacokinetics of flunixin-meglumin in rabbits. $J$ Vet Med Sci 63:885-888.

Ngoh MA, Wislocki PG, Thompson K, Katz T, Weingarten A, TerHune T, and Hurshman B (2003) Residue depletion study and withdrawal period for flunixin- $N$-methyl glucamine in bovine milk following intravenous administration. J Agric Food Chem 51:4701-4707.

Odensvik K and Johansson IM (1995) High-performance liquid chromatography method for determination of flunixin in bovine plasma and pharmacokinetics after single and repeated doses of the drug. Am J Vet Res 56:489-495.

Oltra-Noguera D, Mangas-Sanjuan V, Centelles-Sangüesa A, Gonzalez-Garcia I, Sanchez-Castaño G, Gonzalez-Alvarez M, Casabo VG, Merino V, Gonzalez-Alvarez I, and Bermejo M (2015) Variability of permeability estimation from different protocols of subculture and transport experiments in cell monolayers. J Pharmacol Toxicol Methods 71:21-32.

Otero JA, Barrera B, de la Fuente A, Prieto JG, Marqués M, Álvarez AI, and Merino G (2015) Short communication: the gain-of-function Y581S polymorphism of the ABCG2 transporter increases secretion into milk of danofloxacin at the therapeutic dose for mastitis treatment. $J$ Dairy Sci 98:312-317.

Otero JA, García-Mateos D, Alvarez-Fernández I, García-Villalba R, Espín JC, Álvarez AI, and Merino G (2018) Flaxseed-enriched diets change milk concentration of the antimicrobial danofloxacin in sheep. BMC Vet Res 14:14

Otero JA, García-Mateos D, de la Fuente A, Prieto JG, Álvarez AI, and Merino G (2016) Effect of bovine $A B C G 2$ Y581S polymorphism on concentrations in milk of enrofloxacin and its active metabolite ciprofloxacin. J Dairy Sci 99-5731-5738.

Otero JA, Real R, de la Fuente Á, Prieto JG, Marqués M, Álvarez AI, and Merino G (2013) The bovine ATP-binding cassette transporter ABCG2 Tyr581Ser single-nucleotide polymorphism increases milk secretion of the fluoroquinolone danofloxacin. Drug Metab Dispos 41:546-549.

Pavek P, Merino G, Wagenaar E, Bolscher E, Novotna M, Jonker JW, and Schinkel AH (2005) Human breast cancer resistance protein: interactions with steroid drugs, hormones, the dietary carcinogen 2-amino-1-methyl-6-phenylimidazo(4,5-b)pyridine, and transport of cimetidine. $J$ Pharmacol Exp Ther 312:144-152.

Perez M, Otero JA, Barrera B, Prieto JG, Merino G, and Alvarez AI (2013) Inhibition of ABCG2/ BCRP transporter by soy isoflavones genistein and daidzein: effect on plasma and milk levels of danofloxacin in sheep. Vet $J$ 196:203-208.

Pulido MM, Molina AJ, Merino G, Mendoza G, Prieto JG, and Alvarez AI (2006) Interaction of enrofloxacin with breast cancer resistance protein (BCRP/ABCG2): influence of flavonoids and role in milk secretion in sheep. $J$ Vet Pharmacol Ther 29:279-287.

Rantala M, Kaartinen L, Välimäki E, Stryrman M, Hiekkaranta M, Niemi A, Saari L, and Pyörälä S (2002) Efficacy and pharmacokinetics of enrofloxacin and flunixin meglumine for treatment of cows with experimentally induced Escherichia coli mastitis. $J$ Vet Pharmacol Ther 25:251-258.

Real R, González-Lobato L, Baro MF, Valbuena S, de la Fuente A, Prieto JG, Alvarez AI, Marques MM, and Merino G (2011) Analysis of the effect of the bovine adenosine triphosphate-binding cassette transporter G2 single nucleotide polymorphism Y581S on transcellular transport of veterinary drugs using new cell culture models. J Anim Sci 89:4325-4338.

Robey RW, Pluchino KM, Hall MD, Fojo AT, Bates SE, and Gottesman MM (2018) Revisiting the role of ABC transporters in multidrug-resistant cancer. Nat Rev Cancer 18:452-464.

Rocha KCE, Pereira BMV, and Rodrigues AC (2018) An update on efflux and uptake transporters as determinants of statin response. Expert Opin Drug Metab Toxicol 14:613-624. 
Ron M, Cohen-Zinder M, Peter C, Weller JI, and Erhardt G (2006) Short communication: a polymorphism in ABCG2 in Bos indicus and Bos taurus cattle breeds. J Dairy Sci 89: 4921-4923.

Rúbies A, Guo L, Centrich F, and Granados M (2016) Analysis of non-steroidal antiinflammatory drugs in milk using QuEChERS and liquid chromatography coupled to mass spectrometry: triple quadrupole versus Q-Orbitrap mass analyzers. Anal Bioanal Chem $\mathbf{4 0 8}$ 5769-5778.

Sanchez MP, Govignon-Gion A, Croiseau P, Fritz S, Hozé C, Miranda G, Martin P, BarbatLeterrier A, Letaïef R, Rocha D, et al. (2017) Within-breed and multi-breed GWAS on imputed whole-genome sequence variants reveal candidate mutations affecting milk protein composition in dairy cattle. Genet Sel Evol 49:68.

Shelver WL, Schneider MJ, and Smith DJ (2016) Distribution of flunixin residues in muscles of dairy cattle dosed with lipopolysaccharide or saline and treated with flunixin by intravenous or intramuscular injection. J Agric Food Chem 64:9697-9701.

Smith DJ, Shelver WL, Baynes RE, Tell L, Gehring R, Li M, Dutko T, Schroeder JW, Herges G, and Riviere JE (2015) Excretory, secretory, and tissue residues after label and extra-label administration of flunixin meglumine to saline- or lipopolysaccharide-exposed dairy cows. J Agric Food Chem 63:4893-4901.

Smith GW, Davis JL, Tell LA, Webb AI, and Riviere JE (2008) Extralabel use of nonsteroidal antiinflammatory drugs in cattle. J Am Vet Med Assoc 232:697-701.
Tamura M, Kondo M, Horio M, Ando M, Saito H, Yamamoto M, Horio Y, and Hasegawa Y (2012) Genetic polymorphisms of the adenosine triphosphate-binding cassette transporters (ABCG2, ABCB1) and gefitinib toxicity. Nagoya J Med Sci 74:133-140.

Tu HP, Min-Shan Ko A, Lee SS, Lee CP, Kuo TM, Huang CM, and Ko YC (2018) Variants of ALPK1 with ABCG2, SLC2A9, and SLC22A12 increased the positive predictive value for gout. $J$ Hum Genet 63:63-70.

van Herwaarden AE and Schinkel AH (2006) The function of breast cancer resistance protein in epithelia barriers, stem cells and milk secretion of drugs and xenotoxins. Trends Pharmacol Sci 27:10-16.

Vlaming MLH, Lagas JS, and Schinkel AH (2009) Physiological and pharmacological roles of ABCG2 (BCRP): recent findings in Abcg2 knockout mice. Adv Drug Deliv Rev 61:14-25.

Wassermann L, Halwachs S, Baumann D, Schaefer I, Seibel P, and Honscha W (2013) Assessment of ABCG2-mediated transport of xenobiotics across the blood-milk barrier of dairy animals using a new MDCKII in vitro model. Arch Toxicol 87:1671-1682.

Address correspondence to: Dr. Gracia Merino, Department of Biomedica Sciences-Physiology, Veterinary Faculty, University of Leon 24071, Campus de Vegazana, Leon, Spain. E-mail: gmerp@unileon.es 